\title{
REVISÃO INTEGRATIVA SOBRE A FORMAÇÃO DE PROFESSORES NA REVISTA RETRATOS DA ESCOLA
}

\author{
Sandra Terezinha Urbanetz ${ }^{1}$ \\ Joana Paulin Romanowski ${ }^{2}$ \\ SIMONE URNAU ${ }^{3}$
}

\begin{abstract}
RESUMO: Este texto apresenta os resultados de um estudo de revisão sistemática do tipo síntese integrativa sobre textos relacionados à formação de professores publicados na revista Retratos da Escola. Problematiza a abordagem dos textos quanto a processos, condições e políticas. O objetivo do estudo é examinar os artigos e sua articulação com o escopo do periódico como espaço de defesa dos interesses da categoria, da educação e do país. A análise toma por referência as categorias: 1) formação inicial e continuada de professores; 2) formação para atuação profissional; e 3) políticas públicas e seus impactos. Os artigos publicados expressam modos de resistência ao denunciarem as contradições das finalidades e condições da formação de professores. Assim, a revista se expressa como espaço de publicação de pesquisas e reflexões sobre o professor como pessoa e trabalhador, zelando pela sua valorização e seu reconhecimento social e profissional.
\end{abstract}

Palavras-chave: Formação de professores. Revisão sistemática. Profissão docente. Revista Retratos da Escola.

\section{INTEGRATIVE REVIEW ON TEACHER TRAINING IN RETRATOS DA ESCOLA JOURNAL}

\begin{abstract}
This paper presents the results of a systematic review study of integrative synthesis type on teacher training in articles published at the journal Retratos da Escola (in Portuguese, School Portraits Journal). It discusses the approach of the texts in terms of processes, conditions, and policies. The aim of the study is to examine the articles and their articulation within the purpose of the journal, that is, to be a place for publications which stand for the interests of the teachers, as a class, of education, and of the country. The analysis takes as reference the following categories: 1) initial and continuing teacher education; 2)
\end{abstract}

\footnotetext{
Este texto resulta de parte da pesquisa realizada no projeto Processos de Formação de Professores: Relações com o Desenvolvimento Profissional Docente, que contou com financiamento de Bolsa Produtividade do CNPq.

1. Instituto Federal do Paraná - Campus Curitiba - Curso de Pedagogia - Curitiba (PR), Brasil. E-mail: sandraurbanetz@gmail.com

2.Centro Universitário Internacional - Programa de Pós-Graduação em Educação e Novas Tecnologias - Curitiba (PR), Brasil. E-mail: joana.romanowski@gmail.com

3.Universidade Tecnológica Federal do Paraná - Campus Toledo - Técnica em Assuntos Educacionais - Curitiba (PR), Brasil. E-mail: simoneurnau@gmail.com

Editor de Seção: Sandra Maria Zákia L. Sousa
} 
training for professional performance; and 3) public policies and their impacts. The published articles show forms of resistance when denouncing the contradictions of the purposes and conditions of teacher training. Therefore, the journal claims to be a space for publishing research and reflections on the teacher, both as an individual and a worker, ensuring their social and professional recognition.

Keywords: Teacher training. Systematic review. Teaching profession. Retratos da Escola.

\section{REVISIÓN INTEGRADORA ACERCA DE LA FORMACIÓN DE PROFESORES EN LA REVISTA RETRATOS DA ESCOLA}

RESUMEN: Este texto presenta los resultados de un estudio de revisión sistemática semejante a la síntesis integradora sobre la formación de profesores en los artículos publicados en la revista Retratos da Escola. Problematiza el abordaje de los textos cuanto a procesos, condiciones y políticas. El objetivo del estudio es el de examinar los artículos y su articulación con el propósito del periódico como espacio de defensa de los intereses de la categoría, de la educación y del país. El análisis toma por referencia las categorías: 1) formación inicial y continuada de profesores; 2) formación para la actuación profesional; y 3) políticas públicas y sus impactos. Los artículos publicados expresan modos de resistencias y valorización profesional. Así, la revista se expresa como espacio de publicación de pesquisas y reflexiones acerca del profesor como persona y trabajador, velando por su valorización y su reconocimiento social y profesional.

Palabras-clave: Formación de profesores. Revisión sistemática. Profesión docente. Revista Retratos da Escola.

\section{Introdução}

A

formação de professores se revela uma temática amplamente discutida e, ao mesmo tempo, desafiada pela complexidade que a acompanha. Este texto se propõe a analisar os artigos vinculados ao tema formação de professores publicados na revista Retratos da Escola, por meio de uma pesquisa do tipo revisão bibliográfica. A perspectiva de análise se define como revisão integrativa por visar à integração de opiniões, conceitos e proposições expressos nos artigos examinados (WHITTEMORE; KNAFL, 2005).

O foco de abordagem é interrogar o conteúdo temático do texto para além do assunto tratado e definido no objeto de estudo. Realiza-se um aprimoramento rigoroso, a fim de compreender a finalidade e os resultados do estudo, bem como evidenciar a potencialidade da argumentação empreendida pelo(s) autor(es). Estados da arte são realizados no campo da formação de professores desde o final da década de 1990, estudos que abrangem teses e dissertações, artigos de periódicos e publicações em eventos, evidenciando as tendências de pesquisa (ROMANOWSKI, 2018) e a preocupação com a formação em todos os níveis e modalidades, por exemplo a formação docente para a educação profissional (URBANETZ, 2012) e a formação continuada como necessidade que se impõe a esses docentes (URNAUER, 2019).

Assim, a escolha desse periódico é intencional, motivada por sua vinculação à Confederação Nacional dos Trabalhadores de Educação (CNTE), instituição que congrega tais trabalhadores com o objetivo 
de defender os interesses da categoria, da educação e do país. Especificamente no campo da pesquisa, busca respaldar a luta dos trabalhadores de educação por políticas públicas focadas no ensino público. Elege como temas a saúde e as condições de vida dos educadores e propõe a análise crítica do Sistema de Avaliação da Educação Básica (SAEB), das condições dos trabalhadores aposentados, entre outras questões. Configura-se, portanto, como espaço de resistência e defesa da educação pública, laica e da melhor qualidade para todos. Desse modo, este artigo tem por finalidade examinar os trabalhos sobre formação de professores publicados desde a criação da revista, considerando o alinhamento com o escopo do periódico nessa perspectiva de proposições de defesa da formação do professor da educação pública, profissional que realiza a educação para promover a humanização de sujeitos autônomos e críticos na construção de novas formas de organização social, mais justas e solidárias. (SAVIANI, 1983; FREITAS, 1995).

No período examinado, entre 2007 e 2019, a formação de professores foi demarcada pela institucionalização de inúmeros programas para a melhoria da formação de professores, como o Programa de Alfabetização na Idade Certa (PNAIC), o Plano Nacional de Formação de Professores da Educação Básica (Parfor), o Pró-letramento (Proinfo Integrado), e o Programa Institucional de Bolsa de Iniciação à Docência (Pibid). Do mesmo modo, as políticas de formação de professores foram alvo de resoluções do CNE, como a Resolução CNE/CP n. 02, de $1^{\circ}$ de julho de 2015 (Diretrizes Curriculares Nacionais para a Formação Inicial em Nível Superior e para a Formação Continuada); a Resolução CNE/CP n. 2, de 20 de dezembro de 2019 (Define as Diretrizes Curriculares Nacionais para a Formação Inicial de Professores para a Educação Básica e Institui a Base Nacional Comum para a Formação Inicial de Professores da Educação Básica; BNCFormação); e o Plano Nacional de Educação, Lei n. 13.005/2014. Todos esses documentos são determinantes no campo da formação de professores e requerem ponderar as possíveis relações com os artigos publicados.

\section{O Estudo Realizado}

O estudo examina os artigos publicados no periódico, desde sua criação, no ano de 2007, até o último número, publicado de 2019. Nesse processo, foram consideradas as indicações para estudos de revisão sistemática (VOSGERAU; ROMANOWSKI, 2014) e revisão integrativa (ROTHER, 2007). Para a definição dos artigos incluídos no estudo, foram observadas as indicações da Campbell Collaboration (2017): 1) identificação do periódico e do tema e das questões norteadoras; 2) definição das palavras-chave para busca: "formação de professores", "formação docente"; e 3) coleta dos dados. Como a organização da revista é feita em alguns números por meio de dossiês, o v. 2, n. 2-3 (2008): "Formação de professores: impasses e perspectivas"; o v. 3, n. 5 (2009): "Funcionário de escola: identidade e profissionalização"; e o v. 6, n. 11 (2012): "Condições de trabalho e saúde dos profissionais da educação" foram considerados em sua totalidade. Os demais artigos foram localizados nos diferentes números do periódico, após o que foi feita a leitura dos resumos para a definição de inclusão, resultando em 33 artigos.

Em seguida, foram feitas leitura, sumarização e análise dos textos, de modo a expressar evidências sobre a temática que permitissem indicar preliminarmente a finalidade e as considerações de resultados. As leituras de revisão se pautam em reunir as considerações sobre um determinado tema, resumindo as evidências por meio de procedimentos explícitos e sistematizados, possibilitados pela descrição densa e objetiva da metodologia (SCHIAVON, 2015). As revisões sistemáticas e das metanálises são ferramentas essenciais para a sumarização de evidências científicas de forma acurada e robusta, como alerta Littel (2018). Nas leituras realizadas, desde a pré-análise até o tratamento dos resultados, fez-se importante a contextualização no campo da formação docente, em que se evidenciam a intencionalidade do processo formativo e as proposições e 
práticas em que se denotam modalidades de formação, preocupações e problemas, bem como as definições das políticas para essa formação. Por meio do estudo realizado, é possível sustentar proposições inerentes aos assuntos discutidos. É nesse contexto de produção e de evidências científicas que a revisão sistemática ganha espaço e relevância.

De acordo com a Campbell Collaboration (2017), uma revisão sistemática tem por finalidade reunir pesquisas disponíveis sobre uma questão específica. Para isso, usam-se procedimentos bem-definidos para localizar, avaliar e sintetizar os resultados relevantes de uma pesquisa, procedimentos esses que são estabelecidos a priori, de modo a garantir que os métodos sejam transparentes e possam ser replicados.

No caso deste estudo, por se tratar de periódico e ter sido indicado o foco, procura-se identificar padrões e temas principais, sintetizando os resultados do estudo na perspectiva de revisão integrativa, a qual possibilita uma compreensão abrangente que resulta em síntese dos estudos examinados (KRAMM, 2019) a fim de indicar o movimento da pesquisa tanto de novas orientações e temáticas quanto de permanências e consolidações. É um estudo de revisão de escopo, com o objetivo de apontar um mapa de evidências e suas lacunas. Tal estudo busca indicar os tipos de estudos abordados e os resultados, gerando um novo texto, expresso como síntese na perspectiva de metanálise. A cobertura é de caráter exaustivo, por examinar todos os números publicados do periódico. O método é de abordagem qualitativa, por incluir análise de conteúdo, síntese interpretativa e síntese temática (LITTEL, 2018).

Como indicado, foi estabelecido critério de inclusão/exclusão, focando em artigos sobre formação de professores. Por meio de uma explícita estratégia de busca com o uso de descritores, realizaram-se codificação sistemática e análise (CAMPBELL COLLABORATION, 2017). A análise de conteúdo seguiu as recomendações de Bardin (2011), quais sejam: pré-análise; exploração do material e tratamento dos resultados; inferência e interpretação; e, por fim, síntese integrativa. As categorias foram estabelecidas por sistema de codificação pela identidade de conteúdos contidos no texto e identificação das unidades de registro, a partir do significado do assunto tratado em cada texto. O processo considera a indicação do assunto no texto e o contexto da argumentação, resultando na unidade de compreensão da categoria. É evidente que as categorias estabelecidas podem não ser consideradas definitivas, mas possíveis, no limite do estudo feito. A revisão integrativa, ainda que se apresente como abordagem metodológica ampla, exige a realização da revisão em abordagem qualitativa.

Para a delimitação das categorias de análise, procuramos levar em consideração a especificidade do objeto de estudo. Nesse sentido, para além dos indicativos de caracterização do corpus documental - autor(es), ano, número da revista, título -, foram observados aqueles especificamente relacionados com os objetivos desta revisão integrativa, quais sejam: assunto abordado; argumentação; metodologia e tipo de estudo; dados obtidos e analisados; e considerações conclusivas. Assim, na categorização dos artigos, adotou-se metodologia de análise de conteúdo por unidades de referência, em que, após leitura inicial ou "flutuante" (BARDIN, 2011), a partir de todos os artigos que integram o corpus, emergiram as categorias.

\section{Categorização do Corpus de Estudo}

Os dados de caracterização do corpus permitem inferir que publicaram na revista Retratos da Escola pesquisadores de diferentes estados brasileiros, mas não de todos. Também indicam que há autores com mais de um artigo sobre formação de professores e que muitos dos autores publicaram artigos sobre outras temáticas em outros números do periódico.

A distribuição dos artigos ao longo do período e em vários números da revista aponta que o campo de formação é um tema transverso no periódico. Evidencia-se a valorização do assunto no periódico, uma 
vez que três dossiês específicos foram diretamente dedicados à formação, além de haver significativo número de publicações de artigos em outros dossiês (33 artigos).

$\mathrm{Na}$ Tabela 1, estão delimitados os artigos que foram selecionados para esta análise.

Tabela 1. Relação de artigos analisados.

\begin{tabular}{|c|c|c|c|}
\hline Seq. & $\operatorname{Autor}(\mathbf{a}) / \mathrm{es}(\mathbf{a s})$ & Título & Ano \\
\hline 01 & Leda Scheibe & Formação de professores no Brasil: a herança histórica & 2008 \\
\hline 02 & Ivany Pino & As TIC na formação a distância: reflexões contemporâneas & 2008 \\
\hline 03 & João Antonio Cabral de Monlevade & Normal de nível médio: atual e prioritário, até quando? & 2008 \\
\hline 04 & Antonio Ibañez Ruiz & $\begin{array}{l}\text { Formação continuada e em áreas específicas: a proposta do } \\
\text { Sistema Nacional Público }\end{array}$ & 2008 \\
\hline 05 & Maria Margarida Machado & $\begin{array}{l}\text { Formação de professores para EJA: uma perspectiva de } \\
\text { mudança }\end{array}$ & 2008 \\
\hline 06 & Carlos Roberto Jamil Cury & Potencialidades e limitações da certificação de professores & 2009 \\
\hline 07 & $\begin{array}{c}\text { Maria Lúcia Gomes Meireles, Maria } \\
\text { Aparecida Moreira, Iraci Balbina } \\
\text { Gonçalves Silva }\end{array}$ & Tutoria no curso de formação: uma experiência concreta & 2009 \\
\hline 08 & $\begin{array}{l}\text { Márcia Angela da S. Aguiar, Leda } \\
\text { Scheibe }\end{array}$ & Formação e valorização: desafios para o PNE 2011/2020 & 2010 \\
\hline 09 & $\begin{array}{l}\text { Zenilde Durli, Maria Pasqual } \\
\text { Schneider }\end{array}$ & $\begin{array}{c}\text { O Ensino Fundamental de nove anos: desafios à formação de } \\
\text { professores }\end{array}$ & 2010 \\
\hline 10 & $\begin{array}{l}\text { Patrícia Julia Souza Coelho, Eliseu } \\
\text { Clementino de Souza }\end{array}$ & $\begin{array}{l}\text { Educação infantil no meio rural de Itaberaba (Bahia): contexto, } \\
\text { formação e práticas educativas }\end{array}$ & 2011 \\
\hline 11 & Andréia Ferreira da Silva & $\begin{array}{c}\text { Escolarização obrigatória e formação de professores para a } \\
\text { educação infantil }\end{array}$ & 2011 \\
\hline 12 & Ivone Garcia Barbosa & O ProInfantil e a formação do professor & 2011 \\
\hline 13 & Helena Costa Lopes de Freitas & $\begin{array}{l}\text { Federalismo e formação profissional: por um sistema unitário } \\
\text { e plural }\end{array}$ & 2012 \\
\hline 14 & $\begin{array}{c}\text { Catarina de Almeida Santos, } \\
\text { Danielle Xabregas Pamplona } \\
\text { Nogueira }\end{array}$ & $\begin{array}{l}\text { Federalismo e formação no EaD - colaboração e sobreposição } \\
\text { de competências entre os entes federados }\end{array}$ & 2012 \\
\hline 15 & Helena Costa Lopes de Freitas & PNE e formação de professores: contradições e desafios & 2014 \\
\hline 16 & Clotenir Damasceno Rabelo & $\begin{array}{l}\text { Formação continuada de alfabetizadores: trajetórias recentes e } \\
\text { distâncias operacionais }\end{array}$ & 2014 \\
\hline 17 & Vera Márcia Marques Santos & $\begin{array}{l}\text { Sexualidade e transexualidade: desafios na formação em } \\
\text { pedagogia }\end{array}$ & 2015 \\
\hline 18 & $\begin{array}{c}\text { Sônia Maria Lima, Maria Andreia } \\
\text { Andrade, Maria Inês Sucupira } \\
\text { Stamatto }\end{array}$ & Ensino Médio no Brasil: a formação docente desde 1990 & 2016 \\
\hline 19 & $\begin{array}{l}\text { Caio Veloso, José Augusto de } \\
\text { Carvalho Mendes Sobrinho }\end{array}$ & $\begin{array}{l}\text { Contribuições da formação continuada na ótica do professor } \\
\text { de Ciências Naturais }\end{array}$ & 2017 \\
\hline
\end{tabular}


Tabela 1. Continuação...

\begin{tabular}{|c|c|c|c|}
\hline Seq. & Autor(a)/es(as) & Título & Ano \\
\hline 20 & $\begin{array}{l}\text { Allan Kenji Seki, Artur de Souza, } \\
\text { Olinda Evangelista }\end{array}$ & A formação docente superior: hegemonia do capital no Brasil & 2017 \\
\hline 21 & $\begin{array}{c}\text { Jaqueline Marcela Villafuerte } \\
\text { Bittencourt, Maria Luz Mardesich } \\
\text { Pérez }\end{array}$ & $\begin{array}{l}\text { O novo rumo da formação docente em Bolívia: um movimento } \\
\text { diferente? }\end{array}$ & 2017 \\
\hline 22 & $\begin{array}{l}\text { Marta Lícia Teles Brito de Jesus, } \\
\text { Maria Couto Cunha }\end{array}$ & $\begin{array}{l}\text { Formação de professoras em nível superior simultânea à } \\
\text { atuação na educação básica }\end{array}$ & 2018 \\
\hline 23 & $\begin{array}{l}\text { Kátia Augusta Curado Pinheiro } \\
\text { Cordeiro da Silva }\end{array}$ & Políticas de formação de professores: construindo resistências & 2018 \\
\hline 24 & $\begin{array}{l}\text { Simone Cristiane Silveira } \\
\text { Eliane Santana Dias De }\end{array}$ & $\begin{array}{l}\text { Corpos e imaginação em movimento brincante: teatro e } \\
\text { literatura na formação de professores }\end{array}$ & 2018 \\
\hline 25 & Helena Costa Lopes de Freitas & $\begin{array}{c}30 \text { anos da Constituição: avanços e retrocessos na formação de } \\
\text { professores }\end{array}$ & 2018 \\
\hline 26 & Monica Ribeiro da Silva & $\begin{array}{l}\text { Impertinências entre trabalho, formação docente e o } \\
\text { referencial de competências }\end{array}$ & 2019 \\
\hline 27 & $\begin{array}{l}\text { Ângela Cristina Alves Albino, } \\
\text { Andréia Ferreira da Silva }\end{array}$ & $\begin{array}{l}\text { BNCC e BNC da formação de pro } \\
\text { formação por com } 1\end{array}$ & 2019. \\
\hline 28 & Isabel Maria Sabino de Farias & $\begin{array}{c}\text { O discurso curricular da proposta para BNC da formação de } \\
\text { professores da educação básica }\end{array}$ & 2019 \\
\hline 29 & $\begin{array}{l}\text { Roselane de Fátima Campos, } \\
\text { Zenilde Durli, Rosânia Campos }\end{array}$ & $\begin{array}{l}\text { BNCC e privatização da educação infantil: impactos na } \\
\text { formação de professores }\end{array}$ & 2019 \\
\hline 30 & Álvaro Moreira Hypólito & BNCC, agenda global e formação docente & 2019 \\
\hline 31 & $\begin{array}{l}\text { Nathália Fernandes Egito Rocha, } \\
\text { Maria Zuleide da Costa Pereira }\end{array}$ & $\begin{array}{l}\text { Base Nacional Comum Curricular: os discursos sobre a } \\
\text { docência }\end{array}$ & 2019 \\
\hline 32 & $\begin{array}{l}\text { Márcia Angela da Silva Aguiar, Luiz } \\
\text { Fernandes Dourado }\end{array}$ & $\begin{array}{c}\text { BNCC e formação de professores: concepções, tensões, atores e } \\
\text { estratégias }\end{array}$ & 2019 \\
\hline 33 & Vera Bazzo, Leda Scheibe & $\begin{array}{l}\text { De volta para o futuro... retrocessos na atual política de } \\
\text { formação docente }\end{array}$ & 2019 \\
\hline
\end{tabular}

Fonte: Elaboração própria segundo dados de pesquisa.

$\mathrm{Na}$ perspectiva da abordagem dos textos em relação à formação de professores, as leituras e as análises denotam que há aqueles que focam no processo de formação, por apresentarem resultados de pesquisa referentes a cursos de formação inicial e continuada. Metodologias diversas são apresentadas nos trabalhos analisados, como pesquisa bibliográfica e documental e etnometodologia. Verifica-se, ainda, a utilização da pesquisa qualitativa descritiva, apresentando-se nas produções o uso de memoriais de formação e entrevistas narrativas de abordagem (auto)biográfica, entrevista semiestruturada e relatos de experiências.

Em relação às referências que fundamentam e sustentam as discussões realizadas nos artigos, são indicados autores: 1) vinculados ao assunto abordado no texto; 2) pesquisadores da formação de professores no Brasil, em Portugal e na Espanha; 3) relacionados ao estudo das políticas públicas em formação de professores; e 4) que versam sobre a abordagem metodológica do estudo. Em alguns artigos, pesquisas anteriores do autor são indicadas. Desse modo, são poucos os indicados em mais de um texto, o que justifica que não seja trazida nesta pesquisa uma lista de autores. 
Ressaltamos que os autores referenciados são pesquisadores que tratam de políticas públicas e da formação de professores e entendem e participam dos movimentos em defesa da educação pública, laica e de qualidade, em todos os níveis. Tais autores explicitam a educação na perspectiva dos direitos sociais e a defesa da democratização da escola em todos os níveis, assegurada quanto a acesso, permanência e gestão. A construção do Estado Democrático de Direito, que tem por fundamentos a soberania, a cidadania, a dignidade da pessoa humana, os valores sociais do trabalho e da livre iniciativa e o pluralismo político, é pauta de fundo no debate posto para as políticas públicas em educação e para a formação de professores.

Assim sendo, explicitam-se a seguir as temáticas presentes na revista, apresentadas com a seguinte configuração: finalidades expressas nos cursos de formação de professores; formação de professores para atuação profissional na educação básica e superior; políticas públicas e seus impactos na formação de professores; e diretrizes da formação e diretrizes curriculares.

Por fim, as categorias advindas das análises do campo da formação de professores expressam artigos em relação aos seguintes temas: 1) formação inicial e continuada de professores; 2) formação para atuação profissional; e 3) políticas públicas e seus impactos na formação de professores.

\section{Formação Inicial e Continuada}

Os artigos que abordam a formação inicial de professores tratam dos cursos a distância, do curso normal e das licenciaturas. A formação do professor é entendida como processo contínuo que compreende antecedentes, a formação básica e a formação continuada, as quais, em sua totalidade, constituem o desenvolvimento profissional (VAILLANT; MARCELO, 2015). A condição dos cursos básicos de formação se expressa dicotomizada e paradoxal: as pesquisas no campo apontam possibilidade de melhoria para uma formação direcionada à educação pública e democrática, valorizando as relações teoria-prática e universidade-escola. No entanto, os cursos mantêm uma formação aligeirada e precária, no rastro das políticas de mercantilização da educação (DINIZ PEREIRA, 2015; SEKI; SOUZA; EVANGELISTA, 2017). Essas questões estão transversas nos artigos examinados, sistematizados de modo integrativo, como descrito a seguir.

Desde os anos de 1980, o movimento pela valorização da educação para todos - e, por conseguinte, da escola e do professor -, proclamado pelas diferentes organizações sociais, entre as quais a CNTE, conferiu na Lei de Diretrizes e Bases da Educação Nacional a definição de uma formação inicial na direção da profissionalização do professor, que se materializa em cursos de licenciatura de nível superior, preferencialmente realizados em universidades. Nesse sentido, o artigo de Leda Scheibe (2008), que aborda a formação de professores a partir de uma recuperação histórica de sua realização no Brasil, destaca as transformações ocorridas e os principais marcos legais da formação docente, marcos esses que refletem os embates entre projetos de sociedade e projetos educativos. A autora ressalta o decorrer dos cursos normais na configuração com a formação superior dos cursos de pedagogia, além de tratar das licenciaturas e de seus desafios. A Lei n. 9394/96 sugere a articulação entre teorias e práticas e a valoração das experiências dos antecedentes de formação, mas não inclui a exigência de formação universitária e as regulações posteriores inspiram uma formação técnico-profissionalizante. Sobressai a falta de integração entre as várias esferas responsáveis pela oferta da educação pública e pela proposição de um sistema nacional de formação docente como herança constituída historicamente. São requeridas iniciativas de caráter tanto conjuntural quanto emergencial para que se ultrapassem as fragmentações. Scheibe, em suas considerações finais, fala sobre a "reestruturação do Ministério da Educação e da Capes (Coordenação de Aperfeiçoamento de pessoal de Nível Superior), 
que passa a ser a agência reguladora dos cursos de formação de professores para a Educação Básica; e [do] Programa de Apoio a Planos de Reestruturação e Expansão das Universidades Federais - REUNI" (2008, p. 49), o que apontava para uma nova esperança de superação da herança daquela desintegração, mas não se cumpre no momento atual - momento, aliás, de retrocesso, como expressa artigo da autora citada em parceria com Bazzo (BAZZO; SHEIBE, 2019).

A discussão sobre a necessidade de atualização do curso normal de nível médio é o propósito de Monlevade (2008). No contexto da sociedade brasileira, almejar o "superior" sem a mediação do normal, para Monlevade (2008), é uma temeridade. O autor atesta que a criação do curso normal, em 1834, além de institucionalizar o estatuto de normalista como marco monumental e especializado na formação do professor primário, baliza a política de formação de professores no Brasil. Contudo, o desmonte realizado pela Lei n. 5692/71 e a massificação da educação de $1^{\circ}$ e $2^{\circ}$ graus na década de 1970 descaracterizam a identidade das escolas normais. Na recomposição da sociedade brasileira, nos anos de 1980, os CEFAM (Centros Específicos de Formação e Aperfeiçoamento do Magistério) buscam resgatar a formação do normal, mas os cursos de pedagogia se apresentam como alternativa de formação naquele momento. Monlevade (2008) pondera sobre as limitações do curso normal, mas o defende como possibilidade de formação profissionalizante de Ensino Médio para as classes trabalhadoras, ao "asseverar que os melhores mestres e mestras são os/as que iniciaram sua formação no normal e a aprofundaram no nível superior, inclusive na pós-graduação" (MONLEVADE, 2008, p. 144). Naquela década, os cursos normais acolhiam um número elevado de matrículas, que depois restringiu-se. Contudo, há governos estaduais que mantêm essa formação para o exercício do magistério nos cursos normais, direcionados, principalmente, à formação do professor para a educação infantil e, por extensão, os anos iniciais do Ensino Fundamental. Essa proposição se reporta mais pelo pouco investimento em educação - professores com formação de nível médio fazem jus a salários menores que os de nível superior - do que pela possibilidade de formação em cursos normais de qualidade, discussão transversalizada por Santos (2015) e retomada a seguir. Contraditoriamente, o autor defende que cursos normais de qualidade possibilitariam uma etapa de formação para a consolidação de um processo formativo consistente.

No âmbito da formação em pedagogia, Santos (2015) discute a inserção da sexualidade na proposta curricular desse curso. Para isso, realiza uma escuta atenta sobre as reflexões das acadêmicas em relação à diversidade sexual, em especial à transexualidade. Mesmo que o curso aborde a temática da diversidade, a problemática discutida nos contextos social e cultural para o reconhecimento da pluralidade de modo a superar o desrespeito e a discriminação se apresenta negada. Portanto, esse é um desafio a ser incorporado na formação. Ainda sobre esse curso, Cintra e Debus (2018) examinam a linguagem teatral e a literatura na formação de professores de crianças. $\mathrm{O}$ estudo se realiza a partir da experiência de um programa de extensão com estudantes, tendo em vista a relação entre a infância e a dimensão poética, as quais perpassam os processos formativos e as práticas dos professores da educação infantil.

Jesus e Cunha (2018) discutem a imposição de formação superior definida pela legislação educacional e trazem a necessidade de considerar-se a subjetividade dos professores em sua formação, pois não são pessoas homogêneas nem passivas. A pesquisa evidenciou os dilemas dos professores quando estão em discussão questões relacionadas à satisfação no que diz respeito à performance e à qualificação profissional.

Tanto Ruiz (2008) quanto Velozo e Sobrinho (2017) discutem momentos diferentes dos cursos de formação continuada. Enquanto Ruiz (2008) contextualiza historicamente tais cursos no intuito de revelar que não é recente a carência de professores em áreas específicas, delineando sugestões para a falta de professores e mudanças necessárias para a formação continuada, Velozo e Sobrinho (2017) apresentam a formação continuada a partir do olhar do professor de Ciências Naturais, demonstrando que a formação continuada possibilita mudanças no ensino dessa área, voltadas à atualização científica, além de proporcionar que novas 
metodologias de ensino possam ser conhecidas. Além disso, essa formação contribui para espaços de reflexão e autoavaliação do professor, o que se efetiva quando realizada de forma colaborativa.

Em conjunto com essa discussão, Pino (2008) busca desvelar a forma como as TIC se apresentam nas propostas de formação de professores na modalidade EAD. Destaca-se o atento olhar para os comprometimentos políticos e ideológicos que o uso das TIC oferece à educação e que trazer a EAD como substituição tecnológica favorece a certificação em massa, não a formação, em que a centralidade do sistema tecnológico impacta no caráter pedagógico quando se trata do processo educativo, da mesma forma que impacta na formação de professores e em sua profissionalização. Meireles, Moreira e Silva (2009) discutem a tutoria no curso Profuncionário para os profissionais da rede de ensino de Silvânia (GO). Para as autoras, com o decorrer do curso, os funcionários perceberam que não eram meros cumpridores de tarefas, passando a se inteirarem acerca do conselho escolar e do Projeto Político-Pedagógico. Ao tutor cabe compromisso profissional e com as relações interpessoais dos envolvidos no programa, estabelecendo relação de pertença à instituição.

Ainda dentro das discussões sobre a formação continuada, Cury (2009) aponta para a necessidade de dispositivos que exijam do poder público o direito à educação, além de mecanismos para seu alcance, pois considera indispensável que se promova a valorização docente. Instituir uma Lei de Responsabilidade Educacional se torna mais uma ferramenta de exigência de uma educação pública e de qualidade, inserida no sistema federativo e democrático, para além da certificação de professores.

Essa discussão se articula com a chamada pedagogia das competências que Albino e Silva (2019) propõem-se a analisar. As autoras situam suas proposições em meio ao cenário internacional de reconfiguração produtiva e seus impactos na formação de professores, afirmando que não se trata de um modelo unitário de formação para o trabalho, pois o exame das competências, em diferentes países, aponta diferentes modos de sistematização no processo de formação dos trabalhadores. As autoras destacam que, na formação de professores, evidencia-se uma associação com as proposições da formação para o trabalho em geral. $\mathrm{O}$ modelo de competências está fundado numa perspectiva economicista dos processos formativos, de modo a resultar em eficiência, produtividade e competitividade, com valorização de práticas esvaziadas de seus fundamentos teóricos; em suma, um saber-fazer.

Desse modo, os artigos expressam um cenário de obstáculos na formação inicial dos professores, desde o curso normal até os cursos de licenciatura. Pesquisadores da formação de professores no Brasil têm destacado a incompletude, o inacabamento e as imperfeições dos cursos de formação docente, por suas composição e organização curricular na relação teoria-prática dadas as condições em que se efetivam. Destacam que o processo de formação, de modo geral, é centrado na transmissão de conhecimentos disciplinares. Na esteira de superação desse estado dos cursos, uma nova formação carece ser completada. De outra vertente, a formação continuada tem se constituído espaço propício, ajudando a minorar as insuficiências. Contudo, a formação continuada envolve poucos docentes e se realiza de modo pontual. Portanto, os artigos contribuem para indicar as precariedades e apontar proposições, principalmente ao indicarem a urgência de que se instaure um sistema nacional de formação de professores, constituído de maneira sólida, consistente e a favor da formação do professor para a escola pública.

\section{Formação para a Atuação Profissional}

A consideração da formação vinculada à futura atuação profissional do professor é um pressuposto que marca as finalidades dos cursos, como expressam os documentos norteadores, desde os primeiros 
pareceres do CBE até as atuais Resoluções do CNE. Esses diversos direcionamentos são discutidos em muitos estudos e pesquisas do campo da formação de professores e os artigos publicados na Revista Retratos da Escola contêm essa discussão.

Os artigos de Coelho e Souza (2011), Silva (2011) e Barbosa (2011) focam na formação para atuação do professor na educação infantil. Barbosa (2011) trata da formação de professores para essa etapa da educação a partir do exame do ProInfantil. Ressalta que essa discussão é de longa data, mas é a partir dos anos 1980 que essa preocupação se apresenta de forma mais sistemática. Essa formação, no entender da autora, é carente de uma política efetiva de formação de professores na educação infantil, pois esse não parece ser objetivo para constituir projetos diferenciados de sociedade e de políticas socioculturais. Por isso, a formação de professores na educação infantil, ao superar uma abordagem centrada em conteúdos e conceitos, favorece compreender o lugar social e cultural que esses professores ocupam na formação da infância. Programas emergenciais, típicos do sistema capitalista, tendem a apresentar pouca efetividade formativa, por se restringirem ao domínio de conteúdos, o que exige dar lugar a novas proposições na construção de políticas públicas de formação docente.

Coelho e Souza (2011), ressaltam as dificuldades existentes para que as práticas educativas dialoguem com as proposições legais no âmbito da educação infantil, além de discutirem a profissionalização docente nessa etapa da educação básica. A pesquisa se desenvolve junto a professoras de creches e pré-escolas públicas de povoados localizados na zona rural do município de Itaberaba (Bahia), a partir de memoriais de formação e entrevistas narrativas de abordagem (auto)biográfica. O desenvolvimento da pesquisa fomentou a discussão acerca das dificuldades enfrentadas no contexto de atuação, como a falta de investimento na formação de professores que atuam na educação infantil.

Silva (2011) aborda a formação de professores para a educação infantil no contexto da Emenda Constitucional n. 59/2009, que trata da expansão da educação obrigatória de 9 para 14 anos, o que implica desafio para essa etapa de educação. Entre os aspectos e desafios apontados, está a superação da dualidade teoria-prática para a compreensão do desenvolvimento da criança em suas diferentes dimensões; uma formação articulada à capacidade de construção de propostas de acompanhamento e avaliação do desenvolvimento infantil. Além disso, faz-se necessária a relação entre as políticas de formação e valorização profissional aliadas às condições de trabalho adequadas, dadas a importância e as especificidades da atuação na educação infantil

A formação docente para a Educação de Jovens e Adultos (EJA) não é uma discussão nova e está presente no artigo de Machado (2008), que apresenta a formação de professores para essa modalidade de educação, em especial, a partir da Lei de Diretrizes e Bases da Educação Nacional (LDBEN) n. 9394/96. A autora destaca que esse tipo de ensino passa por uma reconceituação, ao considerar a história de luta pela educação como direito antes mesmo de instituída essa lei. Trata-se de uma mudança da perspectiva compensatória, provocando impactos para o campo da formação docente. Nessa perspectiva, o papel do GT-18 da Anped é decisivo como espaço de discussões, e ações político-pedagógicas determinantes para desenvolver professores que atuam na EJA.

Seki, Souza e Evangelista (2017) ao discutirem a formação em nível superior de professores para atuarem na educação básica, fazem uma análise da hegemonia capitalista nas diretrizes educacionais. Para o estudo, recorrem aos microdados do Inep (2003 a 2015). Ressaltam que o impacto nefasto da financeirização sobre a formação docente e de trabalhadores promove um gradual esvaziamento das condições objetivas de preparo do docente como vital. São destacados o atrofiamento das licenciaturas nas instituições públicas de ensino e o credenciamento da formação de professores à iniciativa privada. Nota-se, assim, uma certificação em massa, bem como o aligeiramento da formação com ampliação da oferta. Essa discussão também está examinada no texto de Cury (2009). 
Ao se reportar a uma formação direcionada para a atuação profissional, os cursos assumem uma performance de desenvolvimento de competências, de modo geral, no escopo do profissionalismo para uma pedagogia de resultados, accountability. Os artigos ponderam essa submissão da formação voltada à produtividade em detrimento da profissionalidade docente. Com efeito, os artigos zelam por uma formação de aprofundamento, reflexão e melhoria do estatuto da categoria, uma formação ética e emancipadora, não atrofiada aos interesses mercantis.

\section{Políticas Públicas e seus Impactos na Formação de Professores}

As discussões em torno das políticas de formação de professores são basilares para a definição de um sistema de formação, como têm proclamado autores, associações e movimentos em prol da formação docente. Desse modo, nessa categoria estão integrados os artigos da revista Retratos da Escola tratando dos impactos das decisões governamentais que definem as diretrizes e os programas no campo da formação de professores.

Bittencourt e Pérez (2017) realizam uma análise da formação docente a partir de um olhar sobre a mudança estrutural em curso na Bolívia, considerando a promulgação da Constituição Política do Estado (2009) e da Lei da Educação (2010). As contradições na construção de políticas em geral manifestam-se também no âmbito da educação, apresentando conflitos como a dificuldade de implementação da Lei da Educação. As autoras destacam o PROFOCOM (Programa de Formación Complementaria para Maestras y Maestros en Ejercicio), que mobilizou milhares de professores bolivianos e caminha para uma prática pedagógica articuladora das esferas social, comunitária e produtiva. Os estudos sobre as políticas educacionais na Bolívia indicam preocupações parecidas com as dos pesquisadores brasileiros.

Durli e Schneider (2010) analisam os impactos da Lei n. 11.274/06 abordando os desafios lançados à formação, especialmente continuada, de professores no contexto da ampliação do Ensino Fundamental para nove anos, instituída naquela lei. As autoras trazem resultados de uma investigação realizada no ano de 2008, com dados que revelam o impacto e o enfrentamento de dificuldades dos municípios da mesorregião oeste de Santa Catarina. Salientam o impacto que a mudança da lei trouxe para a discussão do currículo e das propostas pedagógicas. Constataram as autoras que a falta de um plano de formação continuada configura um dos problemas fundantes diante dos quais se defronta a ampliação da escolaridade obrigatória. Tais mudanças exigem esforços políticos, pedagógicos e materiais, já que estão imersos em um contexto estrutural. Já Lima, Andrade e Stamatto (2016) examinam a formação docente a partir de uma revisão bibliográfica e documental dos referenciais curriculares nacionais do Ensino Médio, da Lei de Diretrizes e Bases da Educação Nacional e do Plano Nacional de Educação 2014-2024 (PNE). As mudanças curriculares, desde a década de 1990 até os dias atuais, e a análise dos documentos revelam que a oferta de formação inicial e continuada está atrelada a indicadores de melhoria da qualidade do ensino na escola pública e à perspectiva de que a formação docente está associada a novas formas de ensinar e aprender, considerando os avanços científicos e tecnológicos.

Especificamente sobre o PNE, temos muitas publicações que demonstram a preocupação dos pesquisadores. Aguiar e Scheibe (2010) se propõem a debater formação e valorização dos profissionais da educação básica como política pública. O cenário expressa um elevado índice de abandono da docência, diante da precarização das condições de trabalho e da baixa remuneração. Entre os desafios, estão a superação da divisão entre teoria e prática e da fragmentação da formação, além da prática da pesquisa a fim de desenvolver o espírito investigativo na formação do professor. Defende-se uma política nacional para formar e valorizar os profissionais da educação; a criação de centros de formação para esses profissionais em cada Estado; e a 
valorização e o desenvolvimento profissionais. Destacam-se, ainda, jornada de trabalho em uma única escola e implantação do piso salarial profissional nacional para todos os profissionais, garantindo, assim, melhores condições de trabalho docente e coletivo. Freitas (2014) discute a formação inicial e continuada de professores, trazendo uma análise das metas e estratégias do PNE (2014-2024). A universalização do acesso desde a préescola até o Ensino Médio, por meio da Lei n. 12.796/13, exige ampliação na contratação de profissionais de diversas áreas e níveis de ensino, dada a expansão do Ensino Superior público, especialmente para as licenciaturas. Ações como a transformação do Pibid em política de Estado e o aumento da oferta de bolsas estão em pauta, além do acompanhamento dos docentes em início de carreira para apoio no enfrentamento das dificuldades - ou seja, condições de formação e oportunidades que possam desencadear nos jovens o interesse pelo magistério. Em relação à formação continuada, a expansão do corpo docente das licenciaturas se mostra um caminho para que as universidades atuem no sentido da formação dos profissionais que lecionam na educação básica.

Rabelo (2014) aborda a política de formação continuada a partir do PNE (2001-2011) e do PNE (2014-2024), com foco nos alfabetizadores. São destacados como fundamentais os debates nacionais e a atuação colaborativa dos entes federativos entre si. Uma vez que alfabetização e formação de alfabetizadores é um desafio nacional, também o é a superação do abismo existente entre o que se propõe e o que se estabelece como demanda real, além do investimento para essa área.

Os artigos de Freitas (2012) e Santos e Nogueira (2012) discutem a formação a partir do regime de colaboração entre os entes federados. Freitas (2012) aponta os desafios para a criação de um sistema nacional de formação de profissionais da educação, elencando quatro pontos cruciais: a expansão da educação superior pública; condições de igualdade no acesso ao trabalho e à educação para a formação de qualidade; garantia de financiamento público na oferta educacional; e realização da gestão democrática. Santos e Nogueira (2012) apontam as dificuldades para a efetivação do regime de colaboração. Destacam os aspectos legais elencados na Constituição Federal e na LDBEN (Lei n. 9.394, de 1996), em que as análises desembocam nas questões acerca dos entes federativos e de seus papéis diante da formação de professores a distância no Brasil. É basilar que as políticas públicas para a formação docente a distância prescindam de um efetivo regime de colaboração entre os entes federativos na construção de um sistema nacional de educação pautado na clareza de objetivos e responsabilidades de cada instância federativa.

Em relação à Base Nacional Curricular Comum (BNCC) e a seus impactos na formação de professores, Aguiar e Dourado (2019) apresentam o dossiê "BNCC e formação de professores: concepções, tensões, atores e estratégias". Os autores indicam que os artigos estão agrupados em dois eixos: 1) Base Nacional Comum Curricular: concepções e desdobramentos político-pedagógicos na educação básica; e 2) Base Nacional Comum Curricular e Política de Formação dos Professores: limites e interfaces. Nesse dossiê, Albino e Silva (2019) descrevem o contexto em que é aprovada uma proposta que não representa a Base Comum Nacional construída pelo movimento dos educadores ao longo das lutas por uma educação cidadã. Assim, a formação entende os professores como recursos humanos, não sujeitos sociais. Entre as implicações desse modelo, as autoras apontam que as competências são adquiridas, validadas e constantemente atualizadas a fim de garantir a empregabilidade do trabalhador. Farias (2019), ao estudar a "Proposta para Base Nacional Comum da Formação de Professores da Educação Básica”, indica que sua formulação é de caráter privado o teor aponta uma agenda impositiva e o conteúdo está norteado pela concepção de competências. O modo de encaminhamento da proposta se apresenta como "uma inversão do sentido histórico desse construto, no qual se sobreleva a noção de base nacional, alinhada às articulações discursivas da homogeneização, da eficácia e da avaliação", na contramão da valorização do professor e de sua carreira, e pouco contribui para o fortalecimento das licenciaturas (FARIAS, 2019, p. 166). Campos, Durli e Campos (2019) propõem-se 
a analisar as orientações governamentais para a implementação da BNCC, evidenciando a ação de redes empresariais na formação de profissionais da educação infantil. É apresentado o quadro da educação infantil no Brasil, enfatizando o direcionamento orientado pela lógica do mercado no fortalecimento e na legitimação da nova governabilidade neoliberal, em que a atuação coordenada entre os entes governamentais e as redes de filantropia empresarial é orientada pela concepção de governança. São analisadas as BNCC, detalhadamente, assinalando o direcionamento da formação por competências. $O$ estudo não se restringe à formação, pois inclui materiais difundidos pelos sítios de redes empresariais e de empresas vinculadas a essas redes, inaugurando novas formas de intervenção e privatização da educação. Já Hypólito (2019) objetiva mostrar a formação docente no interior das relações entre políticas globais e curriculares. A BNCC, como uma política nacional mais ampla em relação à formação de professores, articula-se como uma proposta com finalidade de retirar das universidades a formação docente e desenvolver um programa em que jovens recém-graduados sejam treinados para tornarem-se docentes em um período curto de dois ou três anos. $\mathrm{O}$ propósito do texto em suma é

demonstrar que há uma agenda global que vai se estruturando localmente, a partir de grupos hegemônicos, nem sempre coesos, ora mais liberais, ora mais ultraliberais, ora neoconservadores e autoritários, mas que têm obtido sucesso em impor sua agenda, que assume formas múltiplas de atender os ditames do mercado e dos interesses conservadores (HYPÓLITO, 2019, p. 199).

Rocha e Pereira (2019) apresentam dados sobre as significações da docência quanto às suas implicações com o discurso da política da BNCC. As identidades profissionais dos professores continuam a ser tensionadas mediante processos regulatórios do currículo, presos às classificações dos sistemas de avaliação. Há uma perda de espaços de autonomia profissional, o que contradiz a Base Curricular Nacional $(\mathrm{BCN})$ - que se fundamenta em princípios que versam sobre a formação e a valorização do magistério - e a BNCC - que se baseia em um conjunto de competências. Embora pareçam semelhantes na nomenclatura, as bases são antagônicas e conflitantes em suas intencionalidades. Silva (2018) analisa o Programa de Residência Pedagógica (PRP) e a BNCC, afirmando que, ao se instituir o programa, foram desconsideradas as experiências de êxito, já em andamento no país, e ignoradas discussões históricas travadas em instituições como ANPEd (Associação Nacional de Pós-Graduação e Pesquisa em Educação), ANFOPE (Associação Nacional pela Formação dos Profissionais da Educação) e ANPAE (Associação Nacional de Política e Administração da Educação). A autora assume a defesa por uma Residência Pedagógica na perspectiva da Pedagogia da Alternância, que garanta autonomia e emancipação, com a formação de professores a partir da epistemologia da práxis, bem como um estudo prático do currículo.

Fechando as discussões sobre as políticas educacionais e seus efeitos na formação dos professores, em Freitas (2018) são analisadas as principais ações desenvolvidas no âmbito da formação a partir da Constituição Federal de 1988, discutindo, ainda, o conteúdo das ações relacionadas à implantação da BNCC. Iniciativas referentes à formação de professores que se alinham à BNCC flexibilizam a formação e desprofissionalizam o magistério, tornando os professores meros "tutores práticos" da BNCC, o que representa, portanto, retrocesso no campo da formação docente. Além disso, a formação sofre redução de responsabilidade das universidades públicas, com repasse para as organizações privadas, as quais assumem diversas formas jurídicas apoiadas por organizações empresariais. Enfatizam-se nesse artigo os retrocessos que, a partir do caráter sócio-histórico da formação de professores a ser reordenado, impõem mobilização para resistir e manter as discussões acerca de finalidades, fins e objetivos da educação. 
Assim, verifica-se, nas discussões sobre os impactos das políticas educacionais desde a Constituição Federal (1988), na definição da Lei n. 9394/96, no PNE e, mais recentemente, na BNCC, o desmonte dos avanços educacionais conseguidos até então. Os artigos se aprofundam no teor desses documentos, dos quais emanam diretrizes voltadas às melhorias construídas em propostas e práticas de superação da subformação e da desvalorização profissional. Os primeiros marcos legais, gestados nos movimentos sociais dos anos 1980, acolhiam políticas para uma educação pública e democrática. No entanto, da intencionalidade dos documentos à sua implementação foram se estabelecendo marcos regulatórios de esvaziamento de promessas de melhoria, programas como Parfor, Pibid, PNAIC e outros, em processo de desativação. O permanente paradoxo revelado em avanços e retrocessos torna determinante a vigilância dos movimentos sociais em prol de mudanças na formação de professores.

\section{Considerações Finais}

A revisão sistemática da produção científica, num total de 33 artigos da revista Retratos da Escola, indica que esses emergem da preocupação com as formações inicial e continuada, bem como com o desenvolvimento profissional dos professores e das políticas educacionais. Os artigos se orientam por valorização e profissionalização do magistério, bem como por melhoria das condições de trabalho. Desse modo, tais textos estão em sintonia com o escopo do periódico a que se destinam, pois respaldam a luta dos trabalhadores da educação por políticas públicas focadas no direcionamento do ensino público.

A abordagem dos artigos inseridos em dossiês se articula com a temática orientadora da discussão do conjunto dos textos. No bojo dos artigos, confirmam-se os compromissos da educação pública, democrática e de igualdade para todos. Há fortes questionamentos provocados por uma formação centrada na racionalidade técnica, o que esvazia um projeto de educação para a emancipação, a autonomia e a formação crítica. Desse modo, os artigos se articulam com os propósitos da defesa dos trabalhadores de educação.

Na perspectiva da sustentação metodológica dos artigos, verifica-se que são resultantes da reflexão sobre a formação existente, pois trazem indicadores e dados sobre os cursos e as políticas que os definem. Assim, a argumentação se constrói numa abordagem crítica, tomando por referência pesquisas e estudos realizados no campo da formação de professores e do(s) próprio(s) autor(es). Muitos(as) deles(as) são pesquisadores(as) de longa data sobre o assunto que propõem. Com efeito, a argumentação é densa, pertinente e coesa. Os artigos que expressam resultados de pesquisa têm menor número, mas não são menos reveladores das contribuições das investigações realizadas.

Quanto às referências presentes nos artigos, o exame dos textos indica que os autores estão articulados com o foco da discussão desenvolvida em cada um deles. Assim, não caberia a organização de uma listagem quantitativa para indicação de autores mais citados, pois a abordagem é integrativa, sem perspectiva quantitativa. Destaca-se que a tendência de indicação de autores vincula-se com estudos na vertente progressista, em busca de análises densas e fundamentadas sobre os impactos das políticas públicas nos processos de formação docente. De modo geral, os autores se alinham com o escopo do periódico, na defesa de uma formação que considere a escola pública e democrática. Muitos artigos se reportam a estudos anteriores do(s) autor(es) por se tratar de assuntos vinculados às pesquisas contínuas.

Os estudos levantados revelam, em sua vasta maioria, a defesa da relação entre a adequada formação de professores, a garantia por condições de trabalho dignas e o compatível financiamento público, considerados pilares para a oferta de educação pública de qualidade por parte dos profissionais que nela atuam. Contraditoriamente, as políticas públicas estão forjadas pelo predomínio da valorização retórica da 
educação e, por consequência, da formação de professores. Os artigos ressaltam as reivindicações populares e da categoria docente por uma educação pública, gratuita e de qualidade. Portanto, a construção de políticas públicas orgânicas com soluções estruturais em substituição às emergenciais se expressa como central na promoção da constituição da docência. No campo da formação, as ações essenciais para a profissionalização e a formação teórico-prática sólida dos professores na busca por uma formação humana, ética, cultural e de melhoria do estatuto da categoria são urgentes. Oxalá outros periódicos se somem a essa perspectiva.

\section{Agradecimentos}

Esse texto é uma singela homenagem à Professora Doutora Leda Schiebe e sua equipe pelo incansável trabalho junto à Retratos da Escola.

\section{Contribuições das Autoras}

Problematização e Conceitualização: Urbanetz ST; Romanowski JP; Urnau S; Metodologia: Urbanetz ST; Romanowski JP; Urnau S; Análise: Urbanetz ST; Romanowski JP; Urnau S; Redação: Urbanetz ST; Romanowski JP; Urnau S.

\section{Referências}

AGUIAR, M. A. S; DOURADO, L. F. BNCC e formação de professores: concepções, tensões, atores e estratégias. Retratos da Escola, Brasília, v. 13, n. 25, p. 33-37, jan./maio 2019. https://doi.org/10.22420/rde. v13i25.990

AGUIAR, M. A. S.; SCHEIBE, L. Formação e valorização: desafios para o PNE 2011/2020. Retratos da Escola, Brasília, v. 4, n. 6, p. 77-90, jan./jun. 2010. https://doi.org/10.22420/rde.v4i6.70

ALBINO, A. C.; SILVA, A. F. BNCC e BNC da formação de professores: repensando a formação por competências. Retratos da Escola, Brasília, v. 13, n. 25, p. 123-135, 2019. https://doi.org/10.22420/rde.v13i25.966

BARBOSA, I. G. O ProInfantil e a formação do professor. Retratos da Escola, Brasília, v. 5, n. 9, p. 385-399, jul./dez. 2011. https://doi.org/10.22420/rde.v5i9.20

BARDIN, L. Análise de conteúdo. Lisboa: Edições 70, 2011.

BAZZO, V.; SCHEIBE, L. De volta para o futuro... retrocessos na atual política de formação docente. Retratos da Escola, Brasília, v. 13, n. 27, p. 669-684, set./dez. 2019. https://doi.org/10.22420/rde.v13i27.1038

BITTENCOURT, J.; PÉREZ, M. L. M. O novo rumo da formação docente em Bolívia: um movimento diferente? Retratos da Escola, Brasília, v. 11, n. 21, p. 483-499, jul./dez. 2017. https://doi.org/10.22420/rde.v11i21.799

CAMPOS, R. F; DURLI, Z.; CAMPOS, R. BNCC e privatização da educação infantil: impactos na formação de professores. Retratos da Escola, v. 13, n. 25, p. 170-185, 2019. https://doi.org/10.22420/rde.v13i25.962 
CAMPBELL Collaboration. Oslo, 2017. https://campbellcollaboration.org. Acesso em: 10 jul. 2019.

CINTRA, S. C. S.; DEBUS, E. S. Corpos e imaginação em movimento brincante: teatro e literatura na formação de professores. Retratos da Escola, Brasília, v. 12, n. 23, p. 373-389, jul./out. 2018. https://doi.org/10.22420/ rde.v12i23.872

COELHO, P. J. S.; SOUZA, E. C. Educação infantil no meio rural de Itaberaba (Bahia): contexto, formação e práticas educativas. Retratos da Escola, Brasília, v. 5, n. 9, p. 341-355, jul./dez. 2011. https://doi.org/10.22420/ rde.v5i9.16

CURY, C. R. J. Potencialidades e limitações da certificação de professores. Retratos da Escola, Brasília, v. 3, n. 4, p. 117-134, jan./jun. 2009. https://doi.org/10.22420/rde.v3i4.106

DINIZ-PEREIRA, J. E. A situação atual dos cursos de licenciatura no Brasil frente à hegemonia da educação mercantil e empresarial. Revista Eletrônica de Educação, São Carlos, v. 9, p. 273-280, 2015. https://doi. org/10.14244/198271991355

DURLI, Z.; SCHNEIDER, M. P. O Ensino Fundamental de nove anos: desafios à formação de professores. Retratos da Escola, Brasília, v. 4, n. 7, p. 329-340, jul./dez. 2010. https://doi.org/10.22420/rde.v4i7.90

FARIAS, I. M. S. O discurso curricular da proposta para BNC da formação de professores da educação básica. Retratos da Escola. v. 13, n. 25, p. 155-168, 2019. https://doi.org/10.22420/rde.v13i25.961

FREITAS, H. C. L. Federalismo e formação profissional: por um sistema unitário e plural. Retratos da Escola, Brasília, v. 6, n. 10, p. 211-225, jan./jun. 2012. https://doi.org/10.22420/rde.v6i10.180

FREITAS, H. C. L. PNE e formação de professores: contradições e desafios. Retratos da Escola, Brasília, v. 8, n. 15, p. 427-446, jul./dez. 2014. https://doi.org/10.22420/rde.v8i15.451

FREITAS, H. C. L. 30 anos da Constituição: avanços e retrocessos na formação de professores. Retratos da Escola, Brasília, v. 12, n. 24, p. 511-527, nov./dez. 2018. https://doi.org/10.22420/rde.v12i24.912

FREITAS, L. C. Crítica da organização do trabalho pedagógico e da didática. 10. ed. Campinas: Papirus, 1995.

HYPÓLITO, A. M. BNCC, agenda global e formação docente. Retratos da Escola, Brasília, v. 13, n. 25, p. 187-201, 2019. https://doi.org/10.22420/rde.v13i25.995

JESUS, M. L. T. B. Formação de professoras em nível superior simultânea à atuação na educação básica. Retratos da Escola, Brasília, v. 12, n. 22, p. 73-85, jan./jun. 2018. https://doi.org/10.22420/rde.v12i22.784

KRAMM, D. L. Políticas de formação de professores da educação básica. 2019. 222 f. Tese (Doutorado em Psicologia da Educação) - Faculdade de Educação, PUC-SP, São Paulo, 2019.

LIMA, S. M. P.; ANDRADE, M. A.; STAMATTO, M. I. S. Ensino Médio no Brasil: a formação docente desde 1990. Retratos da Escola, Brasília, v. 10, n. 19, p. 581-595, jul./dez. 2016. https://doi.org/10.22420/ rde.v10i19.544

LITTELL, J. H. Conceptual and practical classification of research reviews and other evidence synthesis products. Campbell Systematic Reviews, Oslo, v. 14, n. 1, p. 1-21, 2018. https://doi.org/10.4073/cmdp.2018.1 
MACHADO, M. M. Formação de professores para EJA: uma perspectiva de mudança. Retratos da Escola, Brasília, v. 2, n. 2-3, p. 161-174, jan./dez. 2008. https://doi.org/10.22420/rde.v2i2/3.133

MEIRELES, M. L. G.; MOREIRA, M. A.; SILVA, I. B. G. Tutoria no curso de formação: uma experiência concreta. Retratos da Escola, Brasília, v. 3, n. 5, p. 463-475, jul./dez. 2009. https://doi.org/10.22420/rde.v3i5.36

MONLEVADE, J. A. C. Normal de nível médio: atual e prioritário, até quando? Retratos da Escola, Brasília, v. 2, n. 2-3, p. 133-148, jan./dez. 2008. Disponível em: http//www.esforce.org.br. Acesso em: 12 abr. 2020.

PINO, I. R. As TIC na formação a distância: reflexões contemporâneas. Retratos da Escola, Brasília, v. 2, n. 2-3, p. 109-120, jan./dez. 2008. https://doi.org/10.22420/rde.v2i2/3.128

RABELO, C. D. Formação continuada de alfabetizadores: trajetórias recentes e distâncias operacionais. Retratos da Escola, Brasília, v. 8, n. 15, p. 533-545, jul./dez. 2014. https://doi.org/10.22420/rde.v8i15.458

ROCHA, N. F. E.; PEREIRA, M. Z. C. Base Nacional Comum Curricular: os discursos sobre a docência. Retratos da Escola. v. 13, n. 25, p. 203-217, 2019. https://doi.org/10.22420/rde.v13i25.964

ROMANOWSKI, J. P. Tendências da pesquisa em formação de professores: entre o local e o universal. Cadernos de Pesquisa, v. 25, p. 207-224, 2018. https://doi.org/10.18764/2178-2229.v25n4p207-224

ROTHER, E. T. Revisão sistemática $\times$ revisão narrativa. Acta Paulista de Enfermagem, São Paulo, v. 20, n. 2, p. v-vi, jun. 2007. https://doi.org/10.1590/S0103-21002007000200001

RUIZ, A. I. Formação continuada e em áreas específicas: a proposta do Sistema Nacional Público. Retratos da Escola, Brasília, v. 2, n. 2-3, p. 149-160, jan./dez. 2008. Disponível em: http//www.esforce.org.br. Acesso em: 20 abr. 2020.

SANTOS, C. A.; NOGUEIRA, D. X. P. Federalismo e formação no EaD - colaboração e sobreposição de competências entre os entes federados. Retratos da Escola, Brasília, v. 6, n. 10, p. 227-240, 2012. https://doi. org/10.22420/rde.v6i10.181

SANTOS, V. M. M. Sexualidade e transexualidade: desafios na formação em pedagogia. Retratos da Escola, Brasília, v. 9, n. 16, p. 111-121, jan./jun. 2015. https://doi.org/10.22420/rde.v9i16.487

SAVIANI, D. Escola e democracia. São Paulo, Cortez/Autores Associados, 1983.

SCHEIBE, L. Formação de professores no Brasil: a herança histórica. Retratos da Escola, Brasília, v. 2, n. 2-3, p. 41-53, jan./dez. 2008. https://doi.org/10.22420/rde.v2i2/3.123

SCHIAVON, S. H. Aplicação da revisão sistemática nas pesquisas sobre formação de professores: uma discussão metodológica. 2015. 95 f. Dissertação (Mestrado em Educação) - Escola de Educação e Humanidades, Pontifícia Universidade Católica do Paraná, Curitiba, 2015.

SEKI, A. K.; SOUZA, A.; EVANGELISTA, O. A formação docente superior: hegemonia do capital no Brasil. Retratos da Escola, Brasília, v. 11, n. 21, p. 447-467, jul./dez. 2017. https://doi.org/10.22420/rde.v1 1i21.812

SILVA, A. F. Escolarização obrigatória e formação de professores para a educação infantil. Retratos da Escola, Brasília, v. 5, n. 9, p. 371-383, jul./dez. 2011. https://doi.org/10.22420/rde.v5i9.19

SILVA, K. A. C. P. C. Políticas de formação de professores: construindo resistências. Retratos da Escola, Brasília, v. 12, n. 23, p. 307-320, jul./out. 2018. https://doi.org/10.22420/rde.v12i23.857 
SILVA, M. R. Impertinências entre trabalho, formação docente e o referencial de competências. Retratos da Escola. Brasília, v. 13, n. 25, p. 123-135, 2019. https://doi.org/10.22420/rde.v13i25.965

VAILLANT, D.; MARCELO, C. El ABC y D de la formación docente. Madrid: Editorial. Narcea, 2015.

VELOSO, C.; SOBRINHO, J. A. C. M. Contribuições da formação continuada na ótica do professor de Ciências Naturais. Retratos da Escola, Brasília, v. 11, n. 20, p. 309-321, jan./jun. 2017. https://doi.org/10.22420/rde. v11i20.597

VOSGERAU, D.; ROMANOWSKI, J. P. Estudos de revisão: implicações conceituais e metodológicas. Revista Diálogo Educacional, Curitiba, v. 14, n. 41, p. 165-189, jan./abr. 2014. https://doi.org/10.7213/dialogo. educ.14.041.DS08

URBANETZ, S. T. Uma ilustre desconhecida: a formação docente para a educação profissional. Revista Diálogo Educacional, Curitiba, v. 12, n. 37, 2012. https://doi.org/10.7213/dialogo.educ.7207

URNAUER, S. Trabalho e educação: uma proposta de formação docente. 2019. 159 f. Dissertação (Mestrado em Educação Profissional e Tecnológica) - Programa de Pós-Graduação em Educação Profissional e Tecnológica, Instituto Federal do Paraná, Curitiba, 2019. Disponível em: http://repositorio.utfpr.edu.br/ jspui/handle/1/4499. Acesso em: 6 maio 2020.

WHITTEMORE, R.; KNAFL, K. The integrative review: updated methodology. Journal of Advanced Nursing, Oxford, v. 52, n. 5, p. 546-553, 2005.

\section{Sobre as Autoras}

Sandra Terezinha Urbanetz é Licenciada em Pedagogia pela Faculdade de Filosofia, Ciências e Letras Tuiuti, e Mestre e Doutora em Educação pela Universidade Federal do Paraná (UFPR). Suas áreas de pesquisa são: Formação docente para a educação profissional; Trabalho; e Educação. http://lattes.cnpq. br/1967514941253300

Joana Paulin Romanowski é bolsista de Produtividade em Pesquisa do CNPq (Nível 1D). Tem Doutorado em Educação pela Universidade de São Paulo (2002), além de Mestrado em Educação, Especialização em Alfabetização e Graduação em Pedagogia pela Universidade Federal do Paraná (UFPR). É coordenadora do Grupo de Pesquisa Práxis Educativa - Dimensões e Processos, com projetos de pesquisa financiados pelo CNPq.

Simone Urnau tem Licenciatura em Letras (Português/Espanhol) pela Universidade Estadual do Oeste do Paraná (UNIOESTE); Especialização em Gestão e Organização Escolar pela Universidade Norte do Paraná (UNOPAR); e Mestrado Profissional em Educação Profissional e Tecnológica (ProfEPT) pelo Instituto Federal do Paraná (IFPR).

Recebido: 11 jul. 2020

Aceito: 31 mar. 2021 